\title{
Product Design Enhancing Environmental Perception and Encouraging Behavioural Change: Eco-Information - the Relationship of Design Styles and User's Emotions
}

\author{
Chanon Tunprawat ${ }^{1}$, Yanin Rugwongwan ${ }^{2}$ \& Wichitra Singhirunnusorn ${ }^{3}$ \\ ${ }^{1}$ Faculty of Architecture, King Mongkut's Institute of Technology Ladkrabang (KMITL), Thailand \\ ${ }^{2}$ School of Interior Architecture, Faculty of Architecture, King Mongkut's Institute of Technology Ladkrabang \\ (KMITL), Thailand \\ ${ }^{3}$ Faculty of Environment and Resource Studies, Mahasarakham University (MSU), Thailand \\ Correspondence: Chanon Tunprawat. Tel: 66-81-908-3970. E-mail: nonimailing@mail.com
}

Received: October 19, 2017

doi:10.5539/ass.v14n1p125

\begin{abstract}
This research is to develop the products that can communicate environmental information to the user. The study investigated design styles of eco-information and impact on user's emotions which can be used as data for product design enhancing environmental perception and encouraging behavioural change. The research aimed to 1) study design styles of eco-information and impact on user's emotions 2) analyse the relationship of design styles and impact on user's emotions effective in promoting environmental behaviour change. Ten-second video clips of seven design styles were presented through a computer and a projector and perception evaluation forms were employed. The sample included 60 students from the Faculty of Architecture and Design, Rajamangala University of Technology Phra Nakhon, Bangkok, Thailand. The results showed that the most effective design style could encourage emotions in the aspects of interest, excitement and preference. This study found that using living creatures to encourage emotions was the most effective attribute. Additionally, giving detailed information through the use of texts and graphs could encourage effectiveness in promoting behavioural change towards energy and resource consumption.
\end{abstract}

Keywords: Behavioural Change, Eco-information, Environmental Perception, Product design, User's Emotions

\section{Introduction}

Human development is dependent on energy and natural resources. At present, the problem of energy shortage and the depletion of natural resources is a big problem. The concept of sustainable development has been adopted as a guideline for driving social, economic and environmental sustainability. Sustainable design is one that is important for sustainable energy. A concept of product design for environmental behaviour enables users to reduce environmental impact by designing product lifecycle (Lilley, 2007), which is the time when users interact with products and energy and resource consumption. The concept also aims to encourage product users to change their behaviour or to enhance chances for users to perceive appropriate behaviour towards product use. Daae (2014) summarises the scope of the theory of Design for Sustainable Behaviour. This theory consists of 3 main components including User-Centred Design, Behavioural Psychology and Sustainability. Bhamra, Lilley, and Tang, (2008) creates the concept of Design Intervention, which considers decision power between product users or product to be a controller and confidence level in behavioural change. This concept is divided into 3 main parts including provision for guidelines for change, behavioural change support and confidence in behavioural change. Design Invention is applied for development of product design, consisting of 7 design methods: Eco-information, Eco-Choice, Eco-Feedback, Eco-Spur, Eco-Steer, Eco-Technical Intervention and Clever Design.

Eco-information and eco-feedback are design methods that communicate useful information to users and that do not force users to use products, enabling users to select to do or not to do on their own. As a result, these methods enable users to have more freedom than other design methods. Eco-information and eco-feedback have been widely studied in the fields of product design, interactive design and computer engineering. At the beginning of design, the focus is on studying information and presentation styles on display that create the 
strongest visual effect on users. Bao, Shaukat, Elantary and Yang (2016) divide eco-information into 2 types, consisting of quantitative information and emotional information. They also suggest that it is important to create balance on these 2 types of information for diverse users so as to create effective design styles that encourage behavioural change. As mentioned earlier, information contents and effective design styles in terms of content

\subsection{Research questions}

1.1.1 How do visualization design styles affect user's emotions?

1.1.2 How is the relationship of design styles and user's emotions related to effectiveness of user's behavioural change?

\subsection{Objectives}

1.2.1 To investigate visualisation design styles in the aspects of eco-information and impact on user's emotions.

1.2.2 To analyse the relationship of design styles and impact on user's emotions effective in promoting user's behaviour change.

\subsection{Literature review}

\subsubsection{Product design and eco-information}

According to previous studies, there are 2 types of visualisation design styles for eco-information for behavioural change.1) Direct information from actual resources. Users can receive information from resources they use directly such as a one litter limited faucet (Do, Kim, \& Oh, 2011) and a towel dispenser made for the WWF (World Wildlife Fund). An advantage is that users are highly encouraged because they receive information directly. However, a disadvantage is that it is only one dimensional-given information, which cannot create other types of information or give essential details. 2) Indirect information via information representatives. Users receive information from monitor or interface via communication representative in different design styles. An advantage of indirect information is that it provides several information dimensions and contents can be altered or added, resulting in more useful and detailed information. However, a disadvantage is that users may be less encouraged when design styles are ineffective.

Eco-information is often indirect information given through interface or monitor, using communication representatives. This is because it can create design styles which better respond to users and is more convenient than direct information. Indirect information also provides more details and its advanced technology can create different design styles. This study applied indirect information.

\subsubsection{Information dimensions}

Information contents communicated to users are important. Previous studies divide information affecting user's behaviour into data granularity, time granularity, comparison and measurement unit (Froehlich, 2011). Petkov et al. (2011) apply the social comparative content to encourage user's energy saving behaviour. Kuznetsov and Paulos (2010) use LED bar graph to display information of average water usage. Kim, Kim and Nam (2009) display impact on nature through electric power extension cords to show changes of trees when high electricity is consumed. Data from usage is mainly focused such as real-time usage, time, real-time cost and environmental impact. However, other information can be presented to users. This study divides information contents into 4 main aspects as follows.

- $\quad$ Fact and situation refers to a widely-used content that presents truth and situation of energy and resource consumption and depletion such as messages or campaign signs that encourage electricity and water supply conservation.

- Usage data refers to a content derived from energy and resource consumption directly including: Volume, Cost, Environmental impacts and Time this content is a main content for eco-information during use-phase of preduct.

- Guideline and suggestion refers to a content that provides appropriate usage in terms of volume such as symbolic display, eco drive mode in automotive that shows appropriate driving speed for energy saving or suggestions for appropriate energy and resource consumption.

- Data for management refers to executed information. For instance, data is calculated or processed before presentation and is used to support decision for energy and resource consumption such as statistical values, values derived from comparison. 
Table 1. Eco-information dimensions and contents

\begin{tabular}{cc}
\hline Eco-information dimensions & Content \\
\hline Fact and situation & -The trend of scarcity of energy and resources available in the world. \\
\hline
\end{tabular}

Table 2. Eco-information dimensions and contents (continuous)

\begin{tabular}{cc}
\hline Eco-information dimensions & Content \\
\hline Fact and situation & - Energy and resources situation \\
Data from usage & - Volume \\
& - Cost \\
& - Time \\
Recommend for use & - Temperature \\
& -Environmental Impacts \\
Information for management & - The appropriate use volume \\
& - The suitable step of use \\
& - Usage statistic \\
& - -Average use \\
\hline
\end{tabular}

\subsubsection{Eco-information visualization design styles}

Design styles have significant aspects because they can increase interest in contents. Previous studies (Froehlich, 2011) propose a concept of eco-feedback design space about primary visual encoding. It is a two-dimension design, combining texture and graphical aspects and pragmatic and artistic aspects. Bao et al. (2016) divide design styles based on clear information and strong emotion into 4 types, including text or chart, colour emphasis, metaphor using object and metaphor using creatures. Laschke, Hassenzahl, Diefenbach and Tippkämper, (2011) use abstract form to design the Shower Calendar (ambient visualization tool) to show water usage volume. Light bulbs are used to design a display to show residential electricity usage (Paay, Kjeldskov, Skov, Lund, Madsen, \& Nielsen, 2014). In addition, design of Amphiro uses a figure of polar bear to design Amphiro_Smart Water Meter to communicate natural impacts that rise from water usage. Design styles are continually explored to increase effectiveness in communication. This research employs 7 design styles to study user's perception as follows.

\section{- $\quad$ Text and Graph}

Refer to a design style that uses alphabets, numbers and graphs to display information. This style is widely used in communication.

\section{- Realistic}

Refer to a design style that uses realistic style to communicate without distorting.

- Icon

Refer to a design style that reduces realistic style to less detailed style yet maintains emotions towards products.

- Index

Refer to a design style that uses figures which are connected to identify or remind users of what is being presented. For instance, smoke is used to remind users of fire or moustache is used to identify masculinity or long hair represents femininity.

- $\quad$ Symbolic

Refer to a design style created to express meaning of a thing which individuals share the same understanding such as on-off signs on electrical appliances, mathematic symbols or traffic signs.

\section{- Abstract}

Refer to a design style with creativity that is not based on realistic style or figures in environment, focusing on making impact on emotions, feelings, thoughts such as colour selection and positions in design.

- $\quad$ Metaphor using living creatures

Refer to a design style that uses living creatures to invoke metaphor. It has been researched in terms of 
eco-feedback and found to have the highest effectiveness in encouraging user's energy saving behaviour.

This research applied Design Style on research of Froehlich (2011) and Bao et al. (2016) as shown in Figure 1

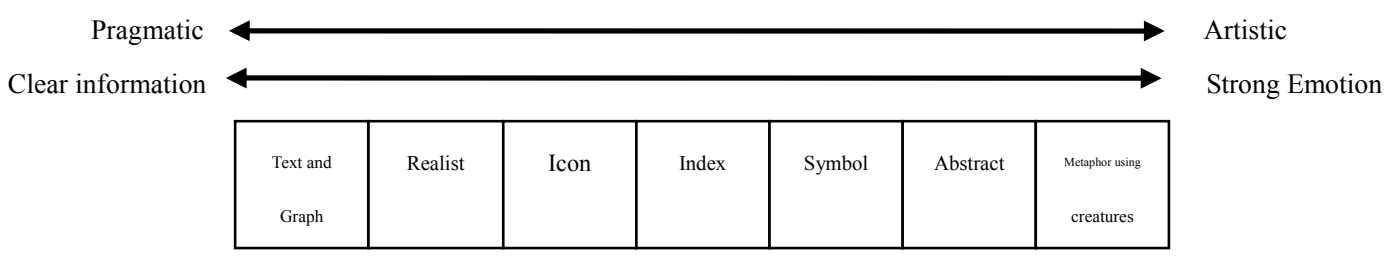

Figure 1. Design style direction on Pragmatic-Artistic form and Clear information-Strong Emotion communication design

\subsubsection{Emotional dimensions}

Emotions towards information and design styles are important to eco-information. An emotion is caused by the interpretation of physical response and the thought of that response (Schachter \& Singer, 1962). In theories of emotions, emotional directions can be divided into 2 types: 1) Pleasantness and 2) Unpleasantness (Harlow and Stagner, 1933).

- Pleasantness consists of positive emotions, encouraging cooperation or effort. This research applied interest, excitement and enjoyment as investigation foundation.

- Unpleasantness consists of negative emotions, encouraging protective, preventive and avoiding behaviour. This research applied anxiety, guilt and depress. This research will lead to emotional directions affecting effectiveness of behavioural change.

\section{Research methodology}

This research investigated the relationship of design styles and user's emotions effective in promoting behavioural change in energy and resource consumption. This research employed a case study to provide data of behavioural change in water usage, simulating water usage situation in public spaces. Images of faucets with screen (Figure 2.) were used as research tools.



Figure 2. The stimuli present the context of water use and samples of design styles

\subsection{Research tools}

Stimuli were 10-second video clips describing 7 design styles. The controlled colour was dark blue and blue which represented water. The content was water usage, considering to be basic information. Numbers were used to display volume of water consumed. 


\subsection{Methods}

Video clips were presented to the sample through a computer screen and a projector in a classroom. Each video clip took 10 seconds. After that, the sample took approximately 5 minutes to evaluate each design style. The entire time was 40-45 minutes.

\subsection{Design evaluation}

This research explored the following aspects.

- Emotions about the design styles

- Clarity in meaningful communication

- Overall preference

- Effectiveness in promoting behaviour change

In this research, evaluations were divided into 2 aspects as follows.

- Evaluation of emotions about the design styles using semantic differential scale on 1-7 level.

- Evaluation of clarity in meaningful communication, overall preference and effectiveness in promoting behavioural change using Likert Scale on 1-7 level.

1. How do you feel about this design style?

$\begin{array}{ccl}\text { Not interesting } & 0000000 & \text { interesting } \\ \text { Not excited } & 0000000 & \text { excited } \\ \text { Not enjoyable } & 0000000 & \text { enjoyable } \\ \text { Not anxious } & 0000000 & \text { anxious } \\ \text { Not guilty } & 0000000 & \text { guilty } \\ \text { Not depressed } & 0000000 & \text { depressed } \\ 2 \text { How clearly does the content in this design? }\end{array}$

2. How clearly does the content in this design?

\begin{tabular}{l|l|l|l|l|l|l|l|l|l|}
\cline { 2 - 4 } Not clearly & 1 & 2 & 3 & 4 & 5 & 6 & 7 & Very clearly
\end{tabular}

3 . Overall, how much do you like this theme?

\begin{tabular}{l|l|l|l|l|l|l|l|}
\cline { 2 - 4 } Dislike & 1 & 2 & 3 & 4 & 5 & 6 & 7
\end{tabular}$\quad$ Very like

4. How effective would this design be in helping you conserve on water use?

Not effective \begin{tabular}{|l|l|l|l|l|l|l|}
\hline 1 & 2 & 3 & 4 & 5 & 6 & 7 \\
\hline
\end{tabular}

Figure 3. The questions example

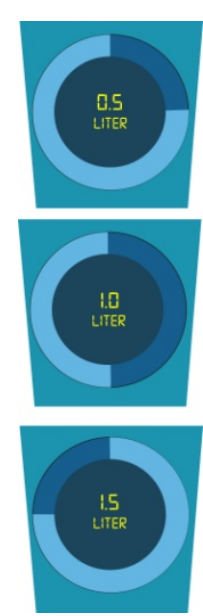

(a)

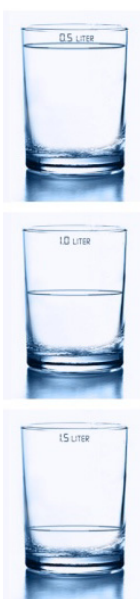

(b)

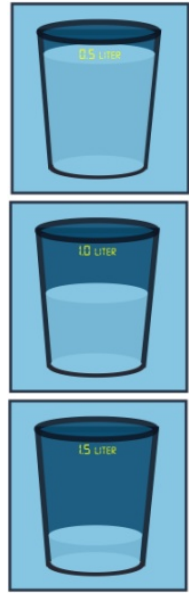

(c)
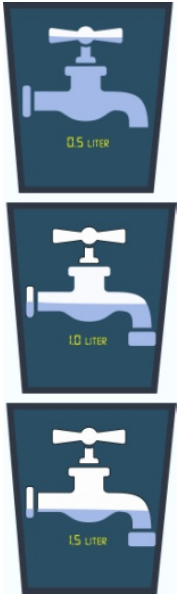

(d)

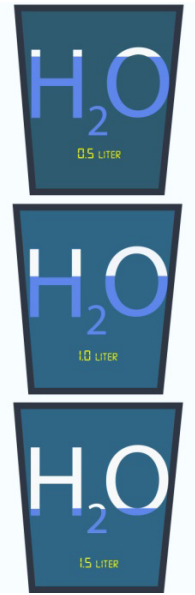

(e)



(f)

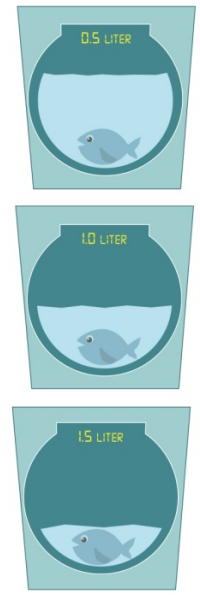

(g)

Figure 4. The stimuli10-second video clips: (a) Text and Graph style (b) Realistic style (c)Iconic Style (d) Indexical Style (e) Symbolic Style (f) Abstract style (g) Metaphor using living creatures style 


\section{Results}

\subsection{Background of respondents}

The sample included 35 male students ( 58.3 percent) and 25 female students ( 41.7 percent). The average age was 19.6 years old (minimum age was 18 and maximum age was 23 years old). Thirty eight students ( 58.3 percent) were the second year students in Industrial Product Program and twenty two students ( 36.7 percent) were the second year students from Package Design Program.

\subsection{Emotions about the design styles}

In overall, emotions about all design styles were at neutral level and tended to slightly positive level. Text and graph style and metaphor using living creatures style were the highest. Details of emotion about each design style are as follows.

\subsubsection{Text and Graph style}

Interest and excitement were high whereas enjoyment, anxiety, guilt and depress were at slightly positive level. Interest was at the highest level ( $\bar{x} 5.40$ S.D. 1.10) whereas depress was at the lowest level ( $\bar{x} 4.43$ S.D. 1.22).

\begin{tabular}{|c|c|c|c|c|c|c|c|}
\hline & $\begin{array}{l}\text { Very } \\
\text { Negative }\end{array}$ & Negative & $\begin{array}{l}\text { Slightly } \\
\text { Negative }\end{array}$ & Neutral & $\begin{array}{l}\text { Slightly } \\
\text { Positive }\end{array}$ & $\begin{array}{c}\text { Very } \\
\text { Positive }\end{array}$ & \\
\hline Not interesting & & & & & 5.40 S.D. & 1.10 & interesting \\
\hline Not excited & & & & & 5.13 S.D. 1.14 & & excited \\
\hline Not enjoyable & & & & & 4.87 S.D. 1.14 & & enjoyable \\
\hline Not anxious & & & & & 4.70 S.D. 1.15 & & anxious \\
\hline Not guilty & & & & & 4.50 S.D. 1.38 & & guilty \\
\hline Not depressed & & & & & 4.43 S.D. 1.22 & & depressed \\
\hline & & 1 & 2 & 3 & 5 & 6 & 7 \\
\hline
\end{tabular}

Figure 5. Emotional dimensions on Text and Graph style

\subsubsection{Realistic style}

In overall, realistic style was at slightly positive level. It was not clearly seen which emotions it affected. Interest was at the highest level ( $\bar{x} 4.70$ S.D. 1.53) whereas anxiety was at the lowest level ( $\bar{x} 4.13$ S.D. 1.43$)$.

\begin{tabular}{|c|c|c|c|c|c|c|c|}
\hline & $\begin{array}{c}\text { Very } \\
\text { Negative }\end{array}$ & Negative & $\begin{array}{l}\text { Slightly } \\
\text { Negative }\end{array}$ & Neutral & $\begin{array}{l}\text { Slightly } \\
\text { Positive }\end{array}$ & $\begin{array}{c}\text { Very } \\
\text { Positive }\end{array}$ & \\
\hline Not interesting & & & & \multicolumn{2}{|r|}{4.70 S.D. 1.53} & & interesting \\
\hline Not excited & & & & \multicolumn{2}{|r|}{ 4.67 S.D. 1.47} & & excited \\
\hline Not enjoyable & & & & \multicolumn{2}{|r|}{4.57 S.D. 1.45} & & enjoyable \\
\hline Not anxious & & & & \multicolumn{2}{|r|}{ 4.13 S.D. 1.43} & & anxious \\
\hline Not guilty & & & & \multicolumn{2}{|r|}{4.33 S.D. 1.45} & & guilty \\
\hline Not depressed & & & & \multicolumn{2}{|r|}{4.70 S.D. 1.24} & & depressed \\
\hline &  & 1 & & & 5 & & \\
\hline
\end{tabular}

Figure 6. Emotional dimensions on Realistic style

\subsubsection{Iconic Style}

Iconic style was at slightly positive level and it was not clearly seen which emotions it affected, similar to realistic style. Interest was at the highest level ( $\bar{x} 4.30$ S.D. 1.24) whereas excitement was at the lowest level $(\bar{x} 4.17$ S.D. 0.95).

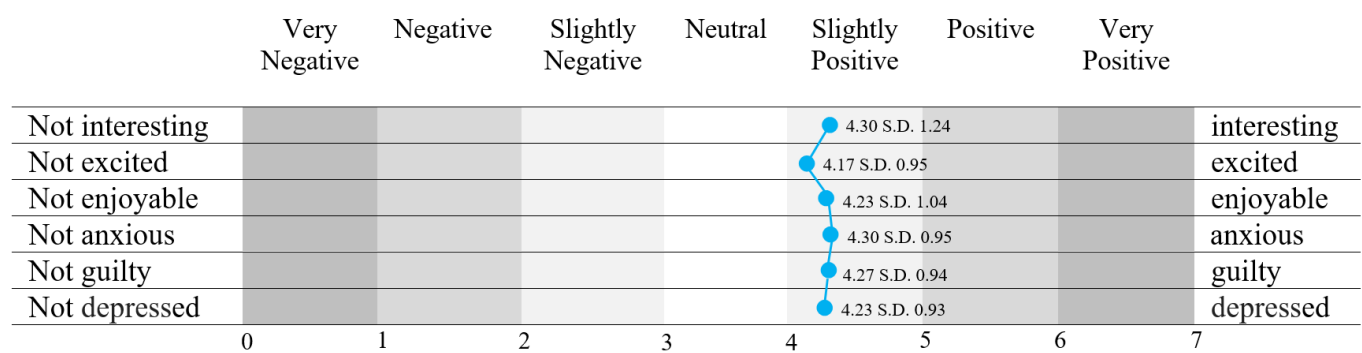

Figure 7. Emotional dimensions on Iconic Style 


\subsubsection{Indexical Style}

In overall, indexical style was at slightly positive level and it was not clearly seen which emotions it affected, similar to iconic style and realistic style. Interest was at the highest level ( $\bar{x} 4.77$ S.D. 1.10$)$ whereas anxiety was at the lowest level ( $\bar{x} 4.07$ S.D. 1.14).

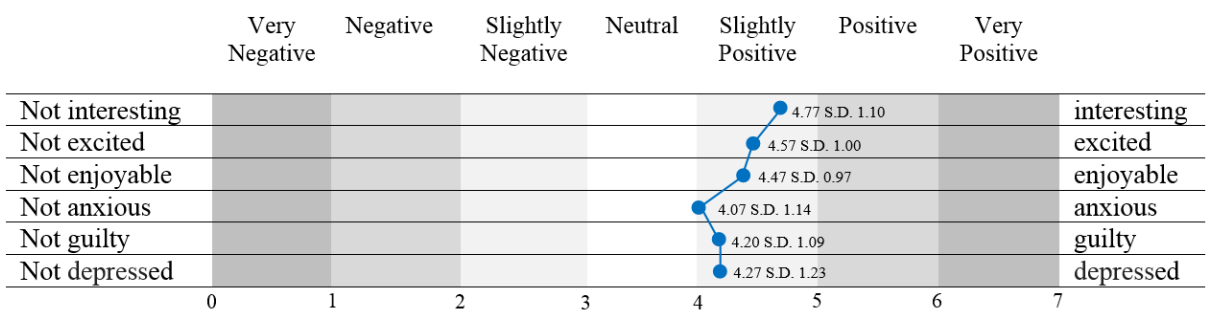

Figure 8. Emotional dimensions on Indexical Style

\subsubsection{Symbolic Style}

In overall, symbolic style was at slightly positive level and it was not clearly seen which emotions it affected, similar to iconic style, realistic style and indexical style. Enjoy was at the highest level ( $\bar{x} 4.73$ S.D. 1.08) whereas anxiety was at the lowest level ( $\bar{x} 4.17$ S.D. 1.02).

\begin{tabular}{|c|c|c|c|c|c|c|c|}
\hline & $\begin{array}{c}\text { Very } \\
\text { Negative }\end{array}$ & Negative & $\begin{array}{c}\text { Slightly } \\
\text { Negative }\end{array}$ & Neutral & $\begin{array}{l}\text { Slightly } \\
\text { Positive }\end{array}$ & $\begin{array}{c}\text { Very } \\
\text { Positive }\end{array}$ & \\
\hline Not interesting & & & & & 4.70 S.D. 1.09 & & interesting \\
\hline Not excited & & & & & 4.47 S.D. 1.25 & & excited \\
\hline Not enjoyable & & & & & 4.73 SD. 1.08 & & enjoyable \\
\hline Not anxious & & & & & 4.17 S.D. 1.02 & & anxious \\
\hline Not guilty & & & & & 4.30 S.D. 1.05 & & guilty \\
\hline Not depressed & & & & & 4.23 S.D. 0.93 & & depressed \\
\hline & & 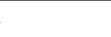 & & & 5 & & 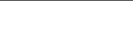 \\
\hline
\end{tabular}

Figure 9. Emotional dimensions on Symbolic Style

\subsubsection{Abstract style}

Abstract style was at slightly positive level and it was not clearly seen which emotions it affected, similar to iconic style, realistic style, indexical style and symbolic style. Interest was at the highest level ( $\bar{x} 4.53$ S.D. 1.00) and guilt was at the lowest level ( $\bar{x}$ 4.23 S.D. 1.04).

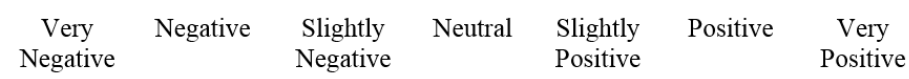



Figure 10. Emotional dimensions on Abstract style

\subsubsection{Metaphor using living creatures style}

Interest, excitement and enjoy were clearly seen at positive level. However, anxiety, guilt and depress were at slightly positive level. Interest was at the highest level ( $\bar{x} 5.47$ S.D. 0.97$)$ whereas anxiety was at the lowest level ( $\bar{x} 4.77$ S.D. 1.04).



Figure 11. Emotional dimensions on Metaphor using living creatures style 


\subsection{Summary design style and emotion}

The design styles that most aroused interest were metaphor using living creatures style ( $\bar{x} 5.47$ S.D. 0.97$)$ and text and graph ( $\bar{x} 5.40$ S.D. 1.10) respectively whereas the design style that least aroused interest was iconic style ( $\bar{x} 4.30$ S.D. 1.24$)$.

The design styles that most aroused excitement were metaphor using living creatures style ( $\bar{x} 5.27$ S.D. 1.08) and text and graph style $(\bar{x} 5.13$ S.D. 1.14) respectively whereas the design style that least aroused excitement was iconic style ( $\bar{x} 4.17$ S.D. 0.95$)$.

The design styles that most aroused enjoyment were metaphor using living creatures style ( $\bar{x} 5.13$ S.D. 1.11 ) and text and graph style ( $\bar{x} 4.87$ S.D. 1.14$)$ respectively whereas the design style that least aroused enjoyment was iconic style ( $\bar{x} 4.23$ S.D. 1.04).

The design styles that most aroused anxiety were metaphor using living creatures style ( $\bar{x} 4.77$ S.D. 1.40$)$ and text and graph style ( $\bar{x} 4.70$ S.D. 1.15$)$ whereas the design style least aroused anxiety was indexical style $(\bar{x}$ 4.07 S.D. 1.14).

The design styles that most aroused guilt were metaphor using living creatures style ( $\bar{x} 4.93$ S.D. 1.53) and text and graph style ( $\bar{x} 4.50$ S.D. 1.39) respectively whereas the design style that least aroused guilt was indexical style ( $\bar{x} 4.20$ S.D. 1.09$)$.

The design styles that most aroused depress were metaphor using living creatures ( $\bar{x} 4.83$ S.D. 1.62$)$ and realistic style ( $\bar{x} 4.50$ S.D. 1.50$)$ respectively whereas the design style that least aroused depress was symbolic style ( $\bar{x} 4.23$ S.D. 0. 93).

Figure 12. Emotional dimensions on Metaphor using living creatures style

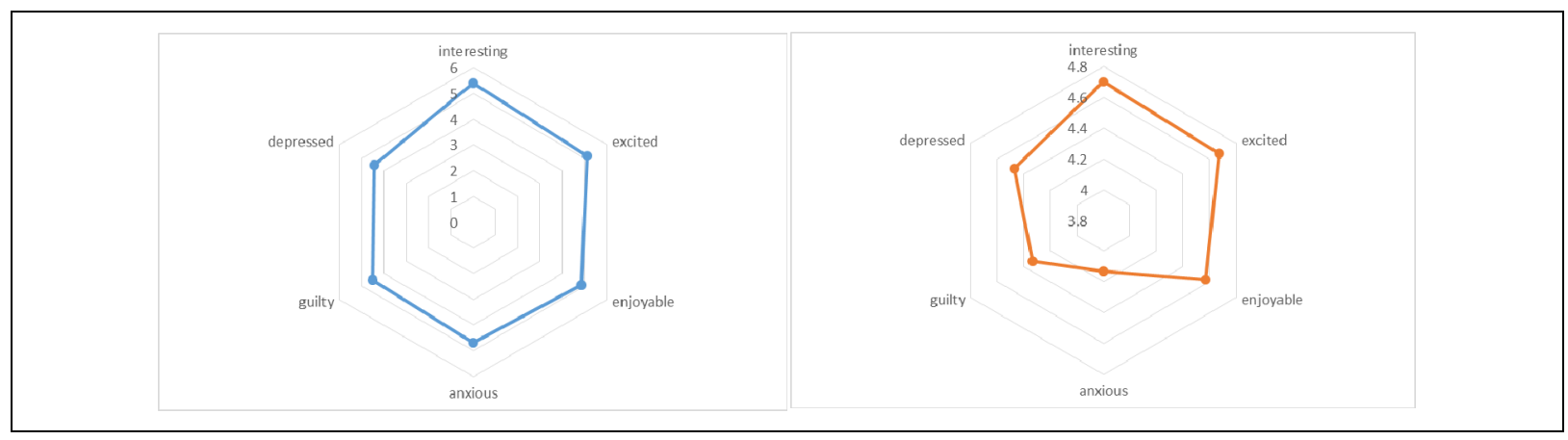

(a)

(b)
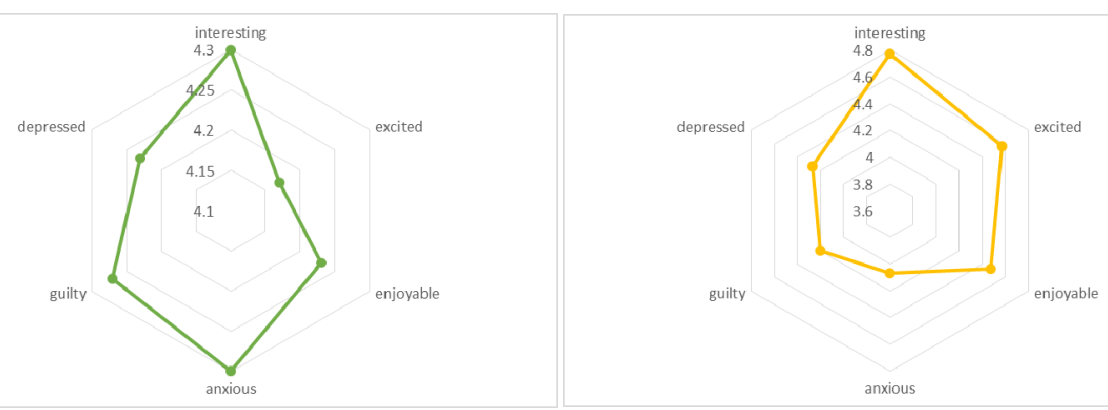

(c)

(d) 


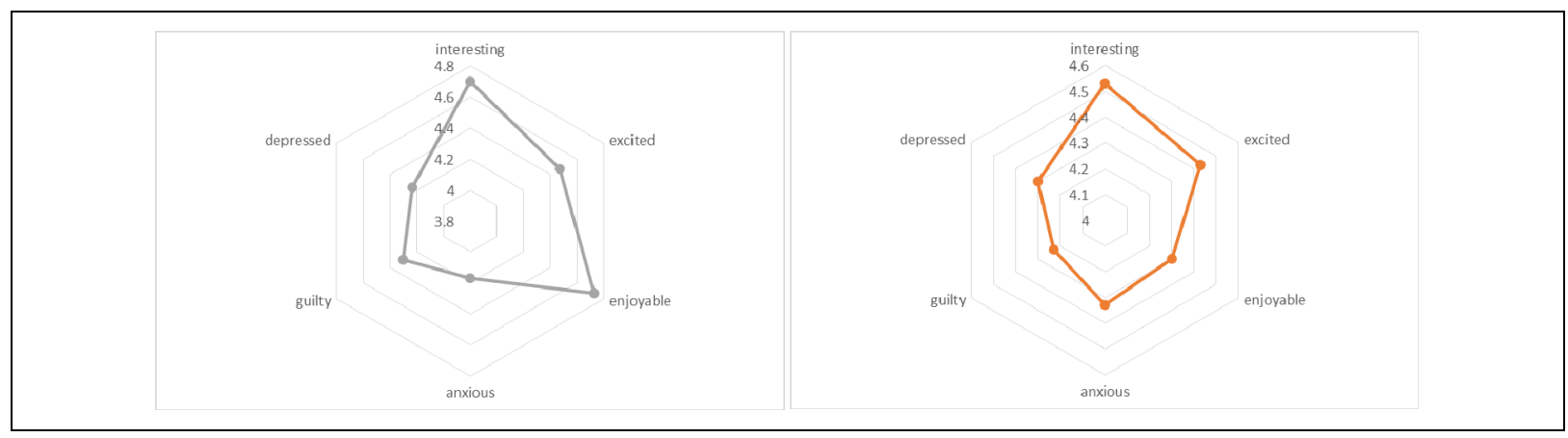

(e)

(f)

Figure 13. Emotional dimensions on the design styles (continuous)
(a)Text and Graph style
(b)Realistic style
(c)Iconic Style
(d)Indexical Style
(e)Symbolic Style
(f)Abstract style

\subsection{Content communication}

The design styles highest evaluated for clarity in meaningful communication were text and graph style $(\bar{x} 5.40$ S.D. 1.20), metaphor using living creatures style ( $\bar{x} 5.23$ S.D. 1.04) and indexical style ( $\bar{x} 5.10$ S.D. 0.96) respectively whereas the design style lowest evaluated for clarity in meaningful communication was realistic style ( $\bar{x} 4.46$ S.D. 1.74$)$.



Figure 14. Clarity in meaningful communication on the design styles

\subsection{Overall preference}

The design styles highest evaluated for clarity in meaningful communication were metaphor using living creatures ( $\bar{x} 5.40$ S.D. 1.20), text and graph style ( $\bar{x} 5.23$ S.D. 1.04$)$ and indexical style ( $\bar{x} 4.80$ S.D. 1.19$)$ respectively whereas the design style lowest evaluated for clarity in meaningful communication was iconic style ( $\bar{x}$ 4.20 S.D. 1.03).

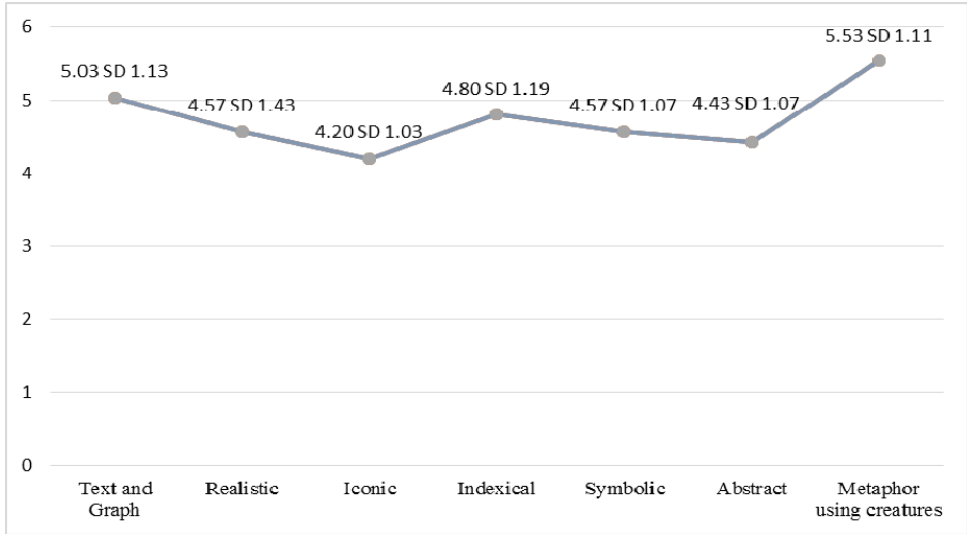

Figure 15. Overall preference level on the design styles 


\subsection{Effectiveness in promoting behavioural change}

The design styles highest evaluated for effectiveness in promoting behavioural change were metaphor using living creatures style ( $\bar{x} 5.17$ S.D. 0.95$)$, text and graph style ( $\bar{x} 4.93$ S.D. 1.11$)$ and indexical style $(\bar{x} 4.87$ S.D. 0.90) whereas the design style lowest evaluated for effectiveness in promoting behavioural change was iconic style ( $\bar{x} 4.37$ S.D. 1.00).



Figure 16. Effectiveness level in promoting behavioural change on the design styles

3.7 The relationship of emotion, clarity of meaningful communication, preference and effectiveness of design styles

Since the design style which was highest evaluated and which had highest effectiveness of meaningful communication was metaphor using living creatures style, the variables of this style was investigated. It was found that it had high correlation among several variables as follows.

Pleasantness: Interesting was highly correlated to excitement (r.859) and excitement was highly correlated to enjoyment (r.846). Unpleasantness: Anxiety was highly correlated to guilt (r.913) and depress (r.944). Clarity of meaningful communication was highly correlated to excitement (r.805). Effectiveness was highly correlated to interest (r.803) and excitement (r.835). Preference was highly correlated to effectiveness (r.832).

Table 3. Correlation level of emotion, clarity of meaningful communication, preference and effectiveness factors

\begin{tabular}{|c|c|c|c|c|c|c|c|c|c|}
\hline & Clarity & Interest & Excitement & Enjoyment & Anxiety & Guilt & Depress & Effectiveness & Preference \\
\hline Clarity & 1.000 & $0.781 * *$ & $0.805^{* *}$ & $0.661 * *$ & $0.420^{*}$ & $0.439 *$ & $0.437 *$ & $0.766^{* *}$ & $.667 * *$ \\
\hline Interest & & 1.000 & $0.859^{* *}$ & $0.693^{* *}$ & 0.297 & 0.332 & 0.253 & $0.803^{* *}$ & $0.760 * *$ \\
\hline Excitement & & & 1.000 & $0.846^{* *}$ & 0.395 & $0.472 *$ & $0.430^{*}$ & $0.835^{* *}$ & $0.700 * *$ \\
\hline Enjoyment & & & & 1.000 & 0.244 & 0.320 & 0.268 & $0.641^{* *}$ & $0.591 * *$ \\
\hline Anxiety & & & & & 1.000 & $0.913 * *$ & $0.913 * *$ & $0.455^{*}$ & 0.219 \\
\hline Guilt & & & & & & 1.000 & $0.944 * *$ & $0.449^{*}$ & 0.137 \\
\hline Depress & & & & & & & 1.000 & $0.473^{*}$ & 0.133 \\
\hline Effectiveness & & & & & & & & 1.000 & $0.832 * *$ \\
\hline Preference & & & & & & & & & 1.000 \\
\hline
\end{tabular}

*Sig .05**Sig .01 (2-tailed)

\section{Conclusion and discussion}

According to data analysis, design styles were at neutral level and tended to slightly positive level. The design styles that created impact on emotions, interest, excitement, enjoyment, anxiety, guilt and depress at the highest level were metaphor using living creatures style, which is consistent with the findings in a study of Bao et.al (2016), and text and graph style respectively. However, several design styles did not demonstrate clarity of directions in the sample's emotions. These design styles included iconic style, realistic style, indexical style, symbolic style and abstract style. Interest was highest evaluated whereas anxiety was lowest evaluated.

Design styles that could encourage user's interest, excitement and overall preference could create impact on effectiveness of promoting behavioural change of energy and natural resource consumption. 


\subsection{Suggestions}

It could be summarised that the most effective design styles could create impact on emotions well. In this research, living creatures were used to arouse emotions. In addition, detailed information given such as text and graph was effective. Consequently, design of information that affects interest, excitement or preference should be taken into account.

This research will collect data from the sample to compare attitude, awareness, behaviour and knowledge about environment that affect effectiveness of data presentation and analyse differences in order to explore and develop product design enhancing environmental perception in the future.

\section{Acknowledgments}

The authors would like to acknowledge Rajamangala University of Technology Phra Nakhon for funding

\section{References}

Bao, Q., Shaukat, M. M., Elantary, A., \& Yang, M. C. (2016). Eco-Feedback: A Balance Between the Quantitative and the Emotional. ASME 2016 International Design Engineering Technical Conferences and Computers and Information in Engineering Conference. 7, 1-12. https://doi:10.1115/DETC2016-59376

Bhamra, T., Lilley, D., \& Tang, T. (2008). Sustainable Use: Changing Consumer Behavior Through Product Design. In Proceedings of Changing the Change: Design Vision, Proposal and Tools, Turin, Italy.

Daae, J. L. (2014). Informing Design for Sustainable Behaviour. Trondheim, Norwey: Norwegian University of Science and Technology.

Do, Y., Kim, D., \& Oh, S. (2011). One Liter Limited. Yanko Desing. Retrieved from http://www.yankodesign.com/2011/02/04/one-liter-limited/

Froehlich, J. E. (2011). Sensing and Feedback of Everyday Activities to Promote Environmental Behaviors (Doctoral dissertation). University of Washington, USA.

Harlow, H. F., Stagner, R. (1933). Psychology of feelings and emotions. II. Theory of emotions. Psychological Review, 40(2), 184-195.

Kim, J. W., Kim, Y. K., Nam, T. J. (2009). The Ténéré: Design for Supporting Energy Conservation Behaviors: Conference on Human Factors in Computing Systems 2010(pp.2643-2646). Boston, MA, USA.

Kuznetsov, S. \& Paulos, E. (2010). UpStream: Motivating Water Conservation with Low-Cost Water Flow Sensing and Persuasive Displays: Conference on Human Factors in Computing Systems 2010 (pp. 1851-1860). Atlanta, Georgia, USA.

Laschke, M., Hassenzahl, M., Diefenbach, S., \& Tippkämper, M. (2011). With a Little Help from a Friend: A Shower Calendar to Save Water: Conference on Human Factors in Computing Systems 2011 (pp.633-646). Vancouver, BC, Canada.

Lilley, D. (2007). Designing for Behavioural Change: Reducing the Social Impacts of Product Use Through Design. Leicestershire, England: Loughborough University.

Paay, J., Kjeldskov, J., Skov, M. B., Lund, D., Madsen, T., \& Nielsen, M. (2014). Design of an Appliance Level Eco-Feedback Display for Domestic Electricity Consumption. Conference on Human Factors in Computing Systems 2014 (pp. 332-341). Sydney, NSW, Australia.

Petkov, P., Medland, R., Köbler, F., Krcmar, H. \& Foth, M. (2011). Engaging Energy Saving through Motivation-Specific Social Comparison: Conference on Human Factors in Computing Systems 2011 (pp. 1945-1950). Vancouver, BC, Canada.

Schachter, S., \& Singer, J. (1962). Cognitive, social, and physiological determinants of emotional state. Psychological Review, 69(5), 379-399. http://dx.doi.org/10.1037/h004623

\section{Copyrights}

Copyright for this article is retained by the author(s), with first publication rights granted to the journal.

This is an open-access article distributed under the terms and conditions of the Creative Commons Attribution license (http://creativecommons.org/licenses/by/4.0/). 